\title{
A low phase angle determined by bioelectrical impedance analysis is associated with oropharyngeal dysphagia among institutionalized older adults
}

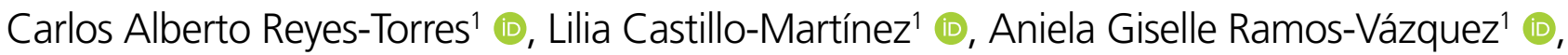 \\ Diana Victoria Chávez-Moreno² 미 Aurora Elizabeth Serralde-Zúñiga *
}

\section{SUMMARY}

OBJECTIVE: The aim was to evaluate the prevalence of oropharyngeal dysphagia (OD) and its association with body composition by bioelectrical impedance analysis (BIA) and functionality among institutionalized older adults.

METHODS: A cross-sectional study was conducted. The swallowing function and diagnosis of OD were evaluated with a volumeviscosity swallow test. Activities of daily living were evaluated by the Barthel Index. Body composition was evaluated by BIA, and phase angle (PhA) was determined.

RESULTS: Eighty institutionalized older adults were evaluated. The mean age of the study population was $82 \pm 9.5$ years, and $65 \%$ were females. The OD prevalence was 30\%, dependence was 30\%, and sarcopenia was $16 \%$. In the multivariate analysis, a low $\mathrm{PhA}\left(<3.5^{\circ}\right)$ was independently associated with the presence of OD adjusted by sex and age (OR: $2.60,95 \% \mathrm{Cl} 2.41-2.90, \mathrm{p}=0.01)$.

CONCLUSIONS: A higher prevalence of OD was found. Significant and independent associations were found between low PhA, dependence, and sarcopenia with the presence of OD among institutionalized older persons.

KEYWORDS: Oropharyngeal dysphagia. Sarcopenia. Home for the aged. Dependence. Clinical. Muscle strength. Nutrition. Nurses. Acute care. Clinical research.

\section{INTRODUCTION}

The aging process causes changes in the anatomy and function of the muscle mass, and these normal processes result in alterations in the swallowing mechanism ${ }^{1}$. In healthy older adults, these changes in swallowing mechanism are known as presbyphagia and do not necessarily imply a pathological condition ${ }^{1,2}$. When these changes occur in sarcopenic, frail, or malnutrition patients, the risk of oropharyngeal dysphagia (OD) increases ${ }^{3}$.

$\mathrm{OD}$ is a high prevalence geriatric syndrome. It has been documented that OD affects $30-40 \%$ of the population aged 65 years and older, recognizing more its clinical, functional, and social importance in the elderly ${ }^{4}$. The prevalence of OD in institutionalized older patients is higher. It is estimated that $40-51 \%$ of institutionalized older patients had the symptoms of $\mathrm{OD}^{5,6}$.

$\mathrm{OD}$ results in clinical and nutritional complications on body composition, nutritional intake, functionality, and prognosis. Over time, the clinical and nutritional complications may lead to frailty, social withdrawal, and mortality ${ }^{6}$. The bioelectrical impedance analysis (BIA) is a noninvasive technique used to estimate body compartments through mechanisms of resistance and reactance and offers an advantage in the assessment of patients with OD. Phase angle $(\mathrm{PhA})$ is an important

\footnotetext{
'Instituto Nacional de Ciências Médicas y Nutrición Salvador Zubirán, Clinical Nutrition Service - Cidade do México, México.

${ }^{2}$ Hospital Juárez de México, Department of Geriatrics - Cidade do México, México.

*Corresponding author: aurora.serraldez@incmnsz.mx

Conflicts of interest: the authors declare there is no conflicts of interest. Funding: none.

Received on June 16, 2021. Accepted on July 14, 2021.
} 
prognosis indicator and a marker of cell membrane integrity evaluated by BIA. Lower PhAs are consistent with muscle mass loss, cell breakdown, and aging cell process, while larger $\mathrm{PhAs}$ are associated with large quantities of healthy cell membranes and body muscle mass .

The handgrip strength (HGS) is used as an indicator of muscle functional capacity in older adults. A recent study conducted by Carrión et al. ${ }^{8}$ demonstrated that $17.4 \%$ of older patients with $\mathrm{OD}$ in a chronic setting had malnutrition evaluated by Mini Nutritional Assessment (MNA) tool, and $16.7 \%$ had Sarcopenia according to the diagnostic criteria recommended by the European Working Group on Sarcopenia in Older People (EWGSOP).

Furthermore, there are few studies that have been evaluated the presence of OD and its association with PhA and HGS in institutionalized older adults. Therefore, the purpose of this study was to evaluate the prevalence of $\mathrm{OD}$ and its association with body composition alterations and functionality among institutionalized older persons.

\section{METHODS}

A cross-sectional study was performed on institutionalized older persons. The Clinical Research and Bioethics Committee approved this study (REF: 1557). All patients who agreed to participate in the study were screened and evaluated after the procedures were explained. Written informed consent was obtained from each participant or the legally authorized representative if the patient was not able to give it.

\section{Swallowing function}

The volume-viscosity swallow test $(\mathrm{V}-\mathrm{VST})^{9}$ was performed to confirm the diagnosis of OD. The V-VST assesses the ability to drink safely and effectively with different types of viscosity and volume. The bolus volume was 5,10 , and $20 \mathrm{~mL}$. The nectar viscosity $(250 \mathrm{cP})$ was achieved by adding $2 \mathrm{~g}$ of the Food Thickener ${ }^{\circledR}$ (Victus Laboratory, FL, USA) to $100 \mathrm{~mL}$ of water, and the pudding viscosity $(800 \mathrm{cP})$ was achieved by adding $5.0 \mathrm{~g}$ of the thickener to $100 \mathrm{~mL}$ of water. Boluses of each volume and viscosity were administered to patients with a syringe during the test to ensure an accurate measurement of the volume. A pulse oximeter was placed on the left index finger before the test, and baseline readings were measured. During the test, the following clinical signs of ineffective swallowing were observed: impaired labial seal, oral residue, and multiple swallows per the bolus. The following clinical signs of unsafe swallowing were also observed according to the V-VST: changes of voice quality, cough, or decrease in oxygen saturation $\geq 3 \%$ to detect silent aspiration ${ }^{9}$.

\section{Mini nutritional assessment}

The nutritional risk was assessed using the MNA questionnaire, a valid and reliable tool to identify malnutrition in elderly people ${ }^{10}$. The original version of this tool that was used for this study contained 18 questions with a maximum of 30 points. It is considered that a score lower than 17 points represents malnutrition ${ }^{11}$.

\section{Barthel index}

Dependence on essential activities of daily living was evaluated by the Barthel Index. It is an ordinal scale that consists of 10 items, namely, personal hygiene, bathing, feeding, transferring to and from a toilet, going upstairs and downstairs, dressing, bowel control, bladder control, bed to chair transfer, and walking on a level surface. Patients were classified as severe dependence with a score $<60$ points $^{12,13}$.

\section{Sarcopenia}

Sarcopenia was diagnosed according to the diagnosis criteria of 2019 guidelines ${ }^{14}$. In the current research, sarcopenia was diagnosed when both low muscle strength measured with HGS and low Skeletal Muscle Mass (SMM) index measured with BIA were present.

The body composition was performed using a single-frequency BIA equipment $(50 \mathrm{kHz}$, Quantum X, RJL Systems, Clinton Township, MI, USA) with the standard technique ${ }^{15}$. With the resistance and the reactance obtained by the BIA, we estimated the SMM to diagnose sarcopenia. SMM was calculated using the equation of Janssen et al. ${ }^{16}$, i.e., SMM (kg): [(Height $\mathrm{cm}^{2} /$ Resistance $\times 0.401)+(\operatorname{sex} \times 3.825)+($ age $x-0.071)+5.102$. For sex, $m e n=1$ and women $=0$, and age is measured in years. Finally, to obtain the Skeletal Muscle Index (SMI), the SMM was divided by the height squared $\left(\mathrm{m}^{2}\right)\left(\mathrm{SMI}=\mathrm{SMM} / \mathrm{Height}^{2}\right)$. The muscular functionality was evaluated with a handgrip dynamometer (TKK 5001 Grip A, Takei Scientific Instruments CO., LTD, Niigata City, Japan). Subjects were placed standing with arms outstretched parallel to the trunk taking the dynamometer and applying maximum strength with each hand without support. The measurement was repeated three times with a separation of 1 min to avoid fatigue, and the maximum value was recorded.

\section{Statistical analysis}

The data are presented as mean \pm standard deviation or median with interquartile range [25-75 th percentile], depending on the data distribution. The Shapiro-Wilk or the KolmogorovSmirnov test for the proper parametric or nonparametric test was performed. For comparisons between groups with $\mathrm{OD}$ and those without OD, a Student's t-test or the Mann-Whitney U test was used for continuous variables. The categorical variables are presented as a percentage, and proportions between 
groups were compared using the chi-squared test. We hypothesized that there would be an association between OD, body composition analysis, and other geriatric syndromes. To identify potential associations between $\mathrm{OD}$ with $\mathrm{PhA}$, sarcopenia, and dependence, a logistic regression analysis was conducted. A p $<0.05$ was considered statistically significant. The data were analyzed using the Statistical Package for the Social Sciences (SPSS Inc., Chicago, IL, USA) version 22.

\section{RESULTS}

A total of 80 residents were evaluated and included in this study. The mean age of the residents was $82 \pm 9.5$ years, and $65 \%$ were females. Table 1 shows the demographics and clinical characteristics of our study population. The prevalence of OD at the evaluation was $30 \%$. The mean score of the MNA was $23 \pm 4$, and the general prevalence of malnutrition (MNA score $<17$ points) was $20 \%$. The most common diagnosis among residents was neurological diseases (i.e., Alzheimer's disease or other dementias) and metabolic disorders (i.e., diabetes mellitus, hypertension, and metabolic syndrome).

The clinical characteristics between study groups are shown in Table 1. The OD group was older $(86 \pm 8.0$ versus $80 \pm 9.4$ years respectively, $\mathrm{p}=0.001$ ) and had the lowest MNA score compared with those residents without OD ( $20 \pm 4$ versus $24 \pm 3$ points, respectively, $\mathrm{p}=0.001)$. The residents with $\mathrm{OD}$ had the lowest HGS (10 \pm 4.9 versus $18 \pm 7.5 \mathrm{~kg}, \mathrm{p}<0.001)$ and $\mathrm{PhA}$ compared with those residents without $\mathrm{OD}(3.5 \pm 0.7$ versus $4.9 \pm 0.8$, $\mathrm{p}<0.001)$. There were significant differences in anthropometric variables and body composition between groups. There were no significant differences in primary diagnosis between groups.

Table 2 contains the associations of OD with some body composition and functionality. Age $>80$ years, the presence of dynapenia, severe dependence, sarcopenia, and low $\mathrm{PhA}$ were significantly associated with the presence of OD in the bivariate analysis. Severe dependence, sarcopenia, and low $\mathrm{PhA}$ were significantly associated with the multivariate analysis adjusted by sex and age. Figure 1 shows the number of subjects with the presence of severe dependence, sarcopenia, and OD. A total of

Table 1. Demographics and clinical characteristics of study subjects.

\begin{tabular}{|c|c|c|c|c|}
\hline & $\begin{array}{l}\text { Total } \\
n=80\end{array}$ & $\begin{array}{c}\text { With OD } \\
n=27\end{array}$ & $\begin{array}{c}\text { Without OD } \\
n=53\end{array}$ & p-value \\
\hline \multicolumn{5}{|l|}{ Sex* } \\
\hline Women, n (\%) & $52(65)$ & $35(44)$ & $45(56)$ & 0.07 \\
\hline Age $\left(\right.$ years) ${ }^{\dagger}$ & $82 \pm 9.5$ & $86 \pm 8.0$ & $80 \pm 9.4$ & 0.001 \\
\hline \multicolumn{5}{|l|}{ Primary diagnosis $(\%)^{*}$} \\
\hline Neurological disease & $27(34)$ & $14(50)$ & $15(28)$ & \multirow{4}{*}{0.30} \\
\hline Cardiopulmonary disease & $15(19)$ & $3(17)$ & $19(10)$ & \\
\hline Metabolic disorders & $27(34)$ & $8(29)$ & $21(40)$ & \\
\hline Other diseases & $11(13)$ & $2(4)$ & $7(13)$ & \\
\hline \multicolumn{5}{|l|}{ ADLs } \\
\hline Barthel index score $^{\dagger}$ & $82 \pm 23$ & $61 \pm 24$ & $92 \pm 14$ & $<0.001$ \\
\hline Dependence $\mathrm{n}(\%)^{*}$ & $24(30)$ & $20(74)$ & $10(18)$ & $<0.001$ \\
\hline \multicolumn{5}{|c|}{ Body composition and functionality } \\
\hline Weight $(\mathrm{kg})^{+}$ & $57 \pm 12$ & $50 \pm 13$ & $61 \pm 11$ & 0.001 \\
\hline Height $(\mathrm{cm})^{\dagger}$ & $148 \pm 11$ & $144 \pm 11$ & $151 \pm 11$ & 0.02 \\
\hline $\mathrm{BMI}\left(\mathrm{kg} / \mathrm{m}^{2}\right)^{\dagger}$ & $25.4 \pm 5.7$ & $23 \pm 7.0$ & $27 \pm 4.5$ & 0.02 \\
\hline $\mathrm{R} / \mathrm{H}(\mathrm{ohms})^{\dagger}$ & $390 \pm 90$ & $440 \pm 103$ & $360 \pm 68$ & $<0.001$ \\
\hline $\mathrm{Xc} / \mathrm{H}(\mathrm{ohms})^{\dagger}$ & $31 \pm 11$ & $28 \pm 6.5$ & $32 \pm 11$ & 0.30 \\
\hline $\operatorname{PhA}\left({ }^{\circ}\right)^{\dagger}$ & $4.4 \pm 1.1$ & $3.5 \pm 0.7$ & $4.9 \pm 0.8$ & $<0.001$ \\
\hline $\mathrm{HGS}(\mathrm{kg})^{\dagger}$ & $15 \pm 5.7$ & $10 \pm 4.9$ & $18 \pm 7.5$ & $<0.001$ \\
\hline
\end{tabular}

OD: oropharyngeal dysphagia; ADLs: activities of daily living; BMI: body mass index; R/H: resistence/height; Xc/H: reactance/height; PhA: phase angle; HGS: handgrip strength; *Proportions were compared with the $\chi^{2}$ test; ${ }^{\dagger}$ The student's t-test was used for comparisons between groups. 
Table 2. Factors associated with oropharyngeal dysphagia.

\begin{tabular}{l|c|c|c|c}
\multirow{2}{*}{} & \multicolumn{2}{|c|}{ Bivariate analysis } & \multicolumn{2}{c}{ Multivariate analysis* } \\
\cline { 2 - 5 } Age $(>80$ years) & OR & $95 \% \mathrm{Cl}$ & OR & $95 \% \mathrm{Cl}$ \\
\hline Malnutrition (MNA) & 3.45 & $1.14-10.37^{+}$ & & \\
\hline Dependence (yes/no) & 2.47 & $0.69-8.88$ & & $2.74-48.06^{+}$ \\
\hline Dynapenia (yes/no) & 12.40 & $3.35-45.94^{+}$ & 11.48 & \\
\hline Sarcopenia (yes/no) & 5.70 & $1.17-27.83^{+}$ & & $1.63-53.53^{+}$ \\
\hline Lower PhA $\left(<3.5^{\circ}\right)$ & 9.40 & $1.30-85.81^{+}$ & 9.33 & $2.41-2.90^{+}$ \\
\hline
\end{tabular}

OR: odds ratio; MNA: mini nutritional assessment, PhA: phase angle; *Multivariate analysis adjusted by sex and age; 'Significant results in bold.

9 residents $(11.4 \%)$ had the triad of geriatric syndromes (i.e., OD, dependence, and sarcopenia).

\section{DISCUSSION}

A cross-sectional study was performed to investigate the OD prevalence and its association with dependence and sarcopenia among institutionalized older adults. We identified two important clinical findings. First, the general OD prevalence was 30\% among residents. Second, severe dependence and sarcopenia were independently associated with the presence of OD, adjusted by sex and age.

The subjects with OD were older, had a higher Barthel Index Score, and had a lower score of MNA. Previous studies ${ }^{17,18}$ have investigated the prevalence and association of malnutrition and dependence in older adults with OD. In a cohort of 1662 hospitalized older persons ${ }^{3}$, it was observed that a Barthel Index Score $<40$ at admission was associated with the presence of OD (OR: 9.71, 95\%CI 7.23-12.04), and subjects with OD had a higher prevalence of malnutrition (68.4\%). Another study conducted among 874 frail older adults ${ }^{19}$ found that dysphagia risk was related to an increased likelihood of malnutrition (OR: $1.30,95 \%$ CI 1.01-1.67). It is important to mention that in these studies the muscle mass index and the muscle strength were not evaluated. In clinical practice, the tools focused to evaluate malnutrition in older adults do not necessarily consider body composition and muscle strength as factors for the diagnosis of malnutrition.

A strength of this study was the evaluation of body composition and the evaluation of muscle strength. A significant association was found between dynapenia and OD. In recent years, the definition and importance of sarcopenic dysphagia have been more studied. Maeda and $\mathrm{Akagi}^{20}$ found a significant correlation between arm muscle area and efficient swallowing in older adults $(\mathrm{r}=0.53, \mathrm{p}<0.05)$. In a cohort of 95 older

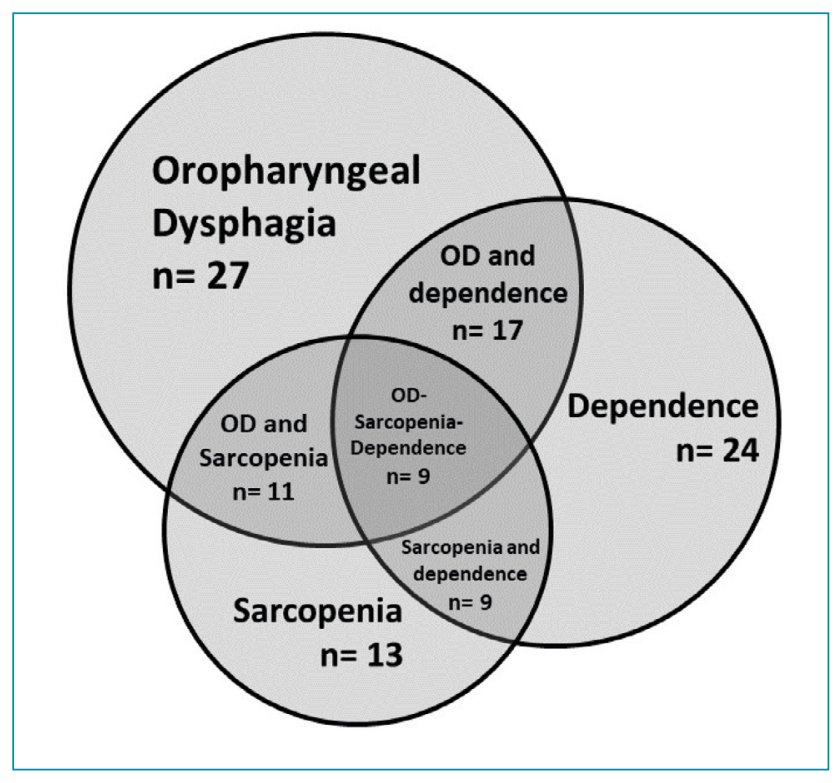

Figure 1. Proportion and association of the three geriatric syndromes studied: oropharyngeal dysphagia, dependence, and sarcopenia.

adults conducted in a care facility, it was found that $77 \%$ of the subjects had sarcopenia, and $26 \%$ developed sarcopenia, all of whom had sarcopenia $(\mathrm{p}=0.002)$. This study concluded that a decreased SMI was associated with the presence of OD (OR: 24.0, 95\%CI 3.6-159.0, $\mathrm{p}=0.001)^{8}$.

Advanced sarcopenia might cause dysphagia, and the loss of activity originated by weakness may result in a reduction in the essential activities of daily living. Although there is an association, it does not imply causality. Some studies have been investigated the association of sarcopenia and impaired swallowing, defined as sarcopenic dysphagia ${ }^{21,22}$. It is important to conduct a complete swallowing evaluation in patients with a diagnosis of sarcopenia or dynapenia to detect alterations in swallowing function. In these older adults with OD and sarcopenia, it is 
important to implement strategies to increase the nutritional intake of energy and protein and to improve the functionality in care facilities.

Our study has important limitations. First, this is a cross-sectional study. We cannot explain causality between sarcopenia with OD and dependence, and the scope of this study is merely descriptive. Second, the sample size was reduced to perform a multivariate analysis adjusted with other confusing variables such as comorbidities, polypharmacy, and nutritional intake. Although it is not a novel concept, this study highlights the current high prevalence of swallowing disorders and the importance of evaluating functionality and body composition among institutionalized older persons.

The presence of geriatric syndromes in institutionalized older adults is highly prevalent and associated with morbidity and poor outcomes. In our findings, a considerable proportion of older adults had the triad of OD, sarcopenia, and dependence. Healthcare providers will increasingly encounter older persons with dysphagia, sarcopenia, and dependence. Evaluating swallowing function and functionality must be part of the screening in institutionalized older adults to implement interventions to recover functional status.

\section{CONCLUSIONS}

OD is frequent and a condition that is underdiagnosed and underestimated among institutionalized older adults. This important condition has a negative effect on the body composition and on the functionality in older adults living in care facilities. Dependence and sarcopenia are geriatric syndromes that are independently associated with the presence of OD.

\section{ACKNOWLEDGMENT}

The authors are grateful to the Centro Gerontológico "Arturo Mundet" for their collaboration in the study.

\section{AUTHORS' CONTRIBUTIONS}

CART: Conceptualization, Methodology, Writing - original draft. LCM: Formal analysis, Investigation, Resources, Software. AGRV: Data curation, Visualization, Writing - original draft. DVCM: Data curation, Visualization, Writing - original draft. AESZ: Supervision, Writing - review \& editing.

\section{REFERENCES}

1. Clavé $P$, Shaker R. Dysphagia: current reality and scope of the problem. Nat Rev Gastroenterol Hepatol. 2015;12(5):259-70. https://doi.org/10.1038/nrgastro.2015.49

2. Humbert IA, Robbins J. Dysphagia in the elderly. Phys Med Rehabil Clin N A. 2008;19(4):853-66, ix-x. https://doi. org/10.1016/j.pmr.2008.06.002

3. Carrión S, Cabré M, Monteis R, Roca M, Palomera E, Serra-Prat $M$, et al. Oropharyngeal dysphagia is a prevalent risk factor for malnutrition in a cohort of older patients admitted with an acute disease to a general hospital. Clin Nutr. 2015;34(3):43642. https://doi.org/10.1016/j.clnu.2014.04.014

4. Roden DF, Altman KW. Causes of dysphagia among different age groups: a systematic review of the literature. Otolaryngol Clin North Am. 2013;46(6):965-87. http://doi.org/10.1016/j. otc. 2013.08.008

5. Melgaard D, Rodrigo-Domingo M, Mørch MM. The prevalence of oropharyngeal dysphagia in acute geriatric patients. Geriatrics (Basel). 2018;3(2):15. https://doi.org/10.3390/ geriatrics3020015

6. Clavé $P$, Verdaguer A, Arreola V. Oral-pharyngeal dysphagia in the elderly. Med Clin (Barc). 2005;124(19):742-8. https:// doi.org/10.1157/13075447

7. Barrea L, Muscogiuri G, Macchia PE, di Somma C, Falco A, Savanelli MC, et al. Mediterranean diet and phase angle in a sample of adult population: results of a pilot study. Nutrients. 2017;9(2):151. https://doi.org/10.3390/nu9020151

8. Carrión S, Roca M, Costa A, Arreola V, Ortega O, Palomera E, et al. Nutritional status of older patients with oropharyngeal dysphagia in a chronic versus an acute clinical situation. Clin Nutr. 2017;36(4):1110-6. https://doi.org/10.1016/j. clnu.2016.07.009
9. Clavé P, Arreola V, Romea M, Medina L, Palomera E, SerraPrat M. Accuracy of the volume-viscosity swallow test for clinical screening of oropharyngeal dysphagia and aspiration. Clin Nutr. 2008;27(6):806-15. https://doi.org/10.1016/j. clnu.2008.06.011

10. Christensson L, Unosson M, Ek AC. Evaluation of nutritional assessment techniques in elderly people newly admitted to municipal care. Eur J Clin Nutr. 2002;56(9):810-8. https://doi. org/10.1038/sj.ejcn.1601394

11. Guigoz Y, Vellas B, Garry PJ. Nutrition surveys in the elderly. Assessing the nutritional status of the elderly: the mini nutritional assessment as part of the geriatric evaluation, Nutrition Reviews. 1996;54(1):S59-S65.

12. Lee $Y C$, Chen $S S$, Koh $C L$, Hsueh IP, Yao KP, Hsieh CL. Development of two barthel index-based supplementary scales for patients with stroke. PLoS One. 2014;9(10):e110494. https://doi.org/10.1371/journal.pone.0110494

13. Diyanto RN, Moeliono MA, Dwipa L. Level of dependency based on barthel and lawton score in older people living in Panti Werdha, Ciparay. Althea Medical Journal. 2016;3(4). https://doi.org/10.15850/amj.v3n4.929

14. Cruz-Jentoft AJ, Bahat $G$, Bauer J, Boirie $Y$, Bruyère $O$, Cederholm T, et al. Sarcopenia: revised european consensus on definition and diagnosis. Age Ageing. 2019;48(1):16-31. https://doi.org/10.1093/ageing/afy169

15. Kyle UG, Genton L, Hans D, Karsegard VL, Michel JP, Slosman DO, et al. Total body mass, fat mass, fat-free mass, and skeletal muscle in older people: cross-sectional differences in 60-year-old persons. J Am Geriatr Soc. 2001;49(12):1633-40. https://doi. org/10.1046/j.1532-5415.2001.t01-1-49272.x 
16. Janssen I, Heymsfield SB, Baumgartner RN, Ross R. Estimation of skeletal muscle mass by bioelectrical impedance analysis. J Appl Physiol (1985). 2000;89(2):465-71. https://doi.org/10.1152/ jappl.2000.89.2.465

17. Streicher M, Wirth $R$, Schindler K, Sieber CC, Hiesmayr M, Volkert D. Dysphagia in nursing homes-results from the NutritionDay Project. JAMDA. 2018;19(2):141-7.e2. https:// doi.org/10.1016/j.jamda.2017.08.015

18. Huppertz VAL, Halfens RJG, van Helvoort A, de Groot LCPGM, Baijens LWJ, Schols JMGA. Association between oropharyngeal dysphagia and malnutrition in dutch nursing home residents: results of the national prevalence measurement of quality of care. J Nutr Health Aging. 2018;22(10):1246-52. https://doi.org/10.1007/s12603018-1103-8
19. Takeuchi K, Aida J, Ito K, Furuta M, Yamashita Y, Osaka K. Nutritional status and dysphagia risk among community-dwelling frail older adults. J Nutr Health Aging. 2014;18(4):352-7. https://doi.org/10.1007/s12603-014-0025-3

20. Maeda K, Akagi J. Decreased tongue pressure is associated with sarcopenia and sarcopenic dysphagia in the elderly. Dysphagia. 2015;30(1):80-7. https://doi.org/10.1007/s00455-014-9577-y

21. Wakabayashi H, Sakuma K. Rehabilitation nutrition for sarcopenia with disability: a combination of both rehabilitation and nutrition care management. J Cachexia Sarcopenia Muscle. 2014;5(4):269-77. https://doi.org/10.1007/s13539-014-0162-x

22. Fujishima I, Fujiu-Kurachi $M$, Arai $H$, Hyodo M, Kagaya $H$, Maeda K, et al. Sarcopenia and dysphagia: position paper by four professional organizations. Geriatr Gerontol Int. 2019;19(2):91-7. https://doi.org/10.1111/ggi.13591 